\title{
Precarização do trabalho da enfermeira obstétrica
}

\author{
Job insecurity among obstetric nurses \\ Precarización del trabajo de la enfermera obstétrica
}

Jane Márcia Progianti'; Noelle Juliana Melo de Paula Moreira"; Juliana Amaral Prata"I";
Manoel Luís Cardoso Vieira ${ }^{\prime v}$; Terezinha Andrade Almeidav ; Octavio Muniz da Costa Vargens ${ }^{\text {VI }}$

\begin{abstract}
RESUMO
Objetivo: refletir sobre as condições objetivas do trabalho, identificadas no perfil sóciodemográfico das enfermeiras obstétricas, que atuam no Sistema Único de Saúde. Metodologia: estudo descritivo, quantitativo, realizado com 15 enfermeiras obstétricas, em 2016 , no Rio de Janeiro. Os dados foram coletados por entrevistas e submetidos à análise estatística simples. Estudo apreciado e aprovado pelo Comitê de Ética em Pesquisa. Resultados: as relações laborais, os salários, o quantitativo de vínculos e a jornada de trabalho das enfermeiras obstétricas, ao serem analisadas de forma associada, apontaram para a precarização do trabalho no serviço público. Conclusão: frente ao avanço da lógica capitalista no Sistema Único de Saúde, é necessário que as enfermeiras obstétricas fortaleçam sua unidade de classe a fim de elaborar estratégias para o enfrentamento dessas condições que deterioram seu processo de trabalho, com grande potencial para comprometer sua saúde e o cuidado às mulheres.
\end{abstract}

Descritores: Enfermagem obstétrica; Mulheres trabalhadoras; Sistemas de saúde; Mercado de trabalho.

\section{ABSTRACT}

Objective: to think about concrete working conditions identified in sociodemographic profiling of obstetric nurses working in Brazil's Unified Health System. Methodology: this quantitative, descriptive study was conducted with fifteen obstetric nurses in Rio de Janeiro, Brazil, in 2016. Data was collected by interview and subjected to statistical analysis. The study was approved by the research ethics committee. Results: taken together, the labor relations, wages, number of jobs, and working hours of obstetric nurses' working in the Brazilian Unified Health System pointed to increasing job insecurity in the public service. Conclusion: considering the advancing influence of capitalist rationale in Brazil's Unified Health System, obstetric nurses need to strengthen their class unity in order to develop strategies for coping with these conditions that are degrading their work process, which has great potential for harming their health and care for women.

Descriptors: Obstetric nursing; Women working; Health systems; Job market.

\section{RESUMEN}

Objetivo: reflexionar sobre las condiciones objetivas del trabajo, identificadas en el perfil sociodemográfico de enfermeras obstétricas, que trabajan en el Sistema Único de Salud. Metodología: estudio descriptivo, cuantitativo, realizado junto a 15 enfermeras obstétricas, en Río de Janeiro, en 2016. Los datos se recolectaron mediante entrevistas y se sometieron al análisis estadístico simple. Estudio revisado y aprobado por el Comité de Ética en Investigación. Resultados: las relaciones laborales, los sueldos, el cuantitativo de vínculos y la jornada de trabajo de las enfermeras obstétricas, al analizarse de forma asociada, apuntaron hacia la precarización del trabajo en el servicio público. Conclusión: considerando el avance de la lógica capitalista en el Sistema Único de Salud brasileño, es necesario que las enfermeras obstétricas fortalezcan su unidad de clase para elaborar estrategias en el sentido de enfrentar las condiciones que deterioran su proceso de trabajo, y que pueden perjudicar su propia salud y comprometer el cuidado de las mujeres.

Descriptores: Enfermería obstétrica; Mujeres trabajadoras; Sistemas de salud; Mercado de trabajo.

\section{INTRODUÇÃO}

Nos anos de 1990, o neoliberalismo conquistava o cenário brasileiro com propostas de reformas envolvendo a contenção de gastos sociais, a privatização de ativos públicos, a desregulamentação do mercado e a globalização da economia ${ }^{1}$.

Paralelamente, modelos flexíveis de gestão e organização do trabalho adentraram no campo laboral, demarcando o início da reestruturação produtiva que pressupõe inovações nos processos produtivos com vistas à reduzir os custos, aumentar a competitividade e melhorar a eficiência².
Essa reconfiguração política, econômica e laboral determinou a redução do papel do Estado nas áreas sociais, com impactos importantes sobre o financiamento do Sistema Único de Saúde (SUS) e, consequentemente, sobre o processo de trabalho em saúde.

De um lado, houve o surgimento de modelos flexíveis de gestão dos serviços e dos recursos humanos, culminando na expansão da rede assistencial, através de parcerias com entidades sem fins lucrativos e Orga-

'Enfermeira. Doutora. Professora Associada. Universidade do Estado do Rio de Janeiro. Rio de Janeiro, Brasil. E-mail: jmprogi@uol.com.br "Enfermeira. Mestre. Secretaria Municipal de Saúde do Rio de Janeiro. Rio de Janeiro, Brasil. E-mail: moreiranoelle86@gmail.com

"'Enfermeira. Doutora. Professora Assistente. Universidade do Estado do Rio de Janeiro. Rio de Janeiro, Brasil. E-mail: juaprata@gmail.com

IvEnfermeiro. Aluno do curso de doutorado em enfermagem. Universidade do Estado do Rio de Janeiro. Rio de Janeiro, Brasil. E-mail: mlcv22@uol.com.br

vEnfermeira. Aluna do curso de doutorado em enfermagem. Universidade do Estado do Rio de Janeiro. Rio de Janeiro, Brasil. E-mail: uerjuesb@gmail.com

viEnfermeiro. Doutor. Professor Titular. Universidade do Estado do Rio de Janeiro. Rio de Janeiro, Brasil. E-mail: omcvargens@uol.com.br 
nizações Sociais (OS), e no advento de diferentes modalidades de vinculação trabalhista na esfera pública. Por outro, as políticas de saúde destacavam a necessidade de repensar o cuidado na perspectiva da integralidade e da autonomia dos indivíduos, valorizando o enfoque no trabalho vivo, aquele que se materializa no ato da interação entre profissional e usuário, e na utilização de tecnologias leves, baseadas nos processos relacionais, em detrimento ao trabalho morto e ao uso de tecnologias duras, características típicas do modelo biomédico, ainda predominante nos serviços de saúde brasileiros ${ }^{3}$.

Nesse contexto, a enfermagem, sobretudo a enfermeira obstétrica, vem se destacando no âmbito da atenção à saúde da mulher como agentes estratégicos para alterar a lógica assistencial, uma vez que o processo de trabalho dessas especialistas apresenta-se centrado no trabalho vivo e no uso de tecnologias leves.

Desse modo, esse estudo objetivou refletir sobre as condições objetivas do trabalho, identificadas no perfil sóciodemográfico das enfermeiras obstétricas, que atuam no Sistema Único de Saúde.

\section{REVISÃo DE LITERATURA}

O modo de produzir o cuidado das enfermeiras obstétricas atende às demandas das políticas públicas ao promover a mudança do modelo de atenção à saúde, melhorar os indicadores maternos e neonatais, assim como reduzir as taxas de cesarianas. Além disso, a atuação dessas especialistas no SUS também é interessante economicamente para a política neoliberal, pois investir num processo de trabalho baseado no trabalho vivo e nas tecnologias leves representa uma forma de reduzir custos ${ }^{3}$.

O reconhecimento dessas potencialidades da enfermeira obstétrica transparece no aumento da participação dessas especialistas na assistência ao parto e na ampliação dos postos de trabalho na atenção à saúde da mulher no âmbito do SUS, principalmente, a partir de 2011 com a implantação da Rede Cegonha, em nível nacional, e do Programa Cegonha Carioca, no município do Rio de Janeiro ${ }^{4-6}$.

Apesar da absorção de enfermeiras obstétricas no mercado laboral do SUS apresentar tendência crescente nos últimos anos, constata-se a existência de diferentes tipos de relações trabalhistas, como o regime estatutário e a contratação por meio das OS, a qual pode ser interpretada como um vínculo fragilizado, pois não garante os mesmos benefícios sociais do servidor público e, por isso, assume uma configuração semelhante ao emprego no setor privado 4 .

Tal configuração de múltiplos vínculos reafirma a flexibilização no setor público, pois as diferenças existentes na relação do servidor estatutário e do trabalhador da OS com o Estado caracterizam uma fragmentação dos vínculos com a administração pública, remetendo a uma das faces da precarização do trabalho no SUS, no que tange as dificuldades de regulação acerca da admissão, demissão e desempenho dos trabalhadores ${ }^{2,7}$.
Para além dessa dimensão, a precarização também pode ser vislumbrada na instabilidade das relações de trabalho, as quais podem apresentar fragilidades quanto aos direitos de proteção social ou nas condições laborais que colocam os trabalhadores em situação de vulnerabilidade, no sentido da insegurança, intensificação e desmotivação ${ }^{1,7}$.

Com a desregulamentação generalizada das condições de trabalho no Brasil, a enfermagem obstétrica se encontra numa posição delicada, onde a precarização pode afetar mais profundamente por se tratar de um processo de trabalho feminino.

\section{Metodologia}

O presente texto constitui um recorte quantitativo de uma pesquisa mais ampla ${ }^{8}$, do tipo descritiva, que buscou analisar os efeitos das condições de trabalho das enfermeiras para o campo obstétrico.

As participantes do estudo foram 15 enfermeiras obstétricas da cidade do Rio de Janeiro, que concluíram sua pós-graduação a partir do final de 2011, ano da implementação de iniciativas governamentais que aumentaram os postos de trabalho para enfermeiras obstétricas noSUS.

Como critérios de inclusão, adotou-se: ter, no mínimo, seis meses de atuação na área obstétrica do setor público e possuir vínculo contratual como enfermeira obstétrica. Como critérios de exclusão, considerou-se: ter menos de seis meses de atuação na área obstétrica; trabalhar somente no setor privado ou possuir vínculo como enfermeira generalista.

A coleta de dados ocorreu no período de abril a maio de 2016, por meio de entrevista semiestruturada, seguindo um roteiro dividido em duas seções. A primeira, contendo questões fechadas que apreenderam, a partir do perfil sociodemográfico das participantes, as condições objetivas do trabalho das enfermeiras obstétricas. A segunda, com questões abertas que captaram as condições subjetivas. As entrevistas aconteceram fora do local de trabalho das participantes e tiveram duração média de 45 minutos.

Para fins deste texto, foram consideradas somente as condições objetivas, definidas como aquelas relacionadas à produção material da sociedade e que estão dadas na realidade material, tais como o vínculo, o salário/rendimentos e a jornada laboral. ${ }^{9}$ Assim, os dados quantitativos produzidos pela primeira parte do roteiro foram analisados por estatística descritiva simples e apresentados sob a forma de frequência absoluta e percentual.

Atendendo à Resolução $n^{\circ} 466 / 2012$, as participantes assinaram um Termo de Consentimento Livre e Esclarecido e preservou-se o anonimato das mesmas. $\mathrm{O}$ estudo foi aprovado pelo Comitê de Ética e Pesquisa da Universidade do Estado do Rio de Janeiro, sob o CAAE 54061315.9.0000.5282 e parecer $n^{\circ} 1.459 .532$.

\section{RESULTADOS E DisCUSSÃo}

No que tange a dimensão objetiva das condições de trabalho das enfermeiras obstétricas entrevistadas, 
constatou-se que dez $(66,66 \%)$ participantes acumulam dois vínculos empregatícios, prevalecendo a relação de trabalho regida pela Consolidação das Leis Trabalhistas (CLT), na modalidade de contratação estabelecida por meio de OS. Quanto aos salários, verificou-se que oito $(53,33 \%)$ possuem renda mensal acima de $R \$ 6.000,00$ e sete $(46,66 \%)$ entre $R \$ 3.500,00$ e $6.000,00$.

Os dados revelam que as oito enfermeiras com renda mensal acima de $\mathrm{R} \$ 6.000,00$, mantém dois vínculos empregatícios no setor público. Desse grupo, seis declararam possuir dois vínculos de contrato do tipo CLT e duas disseram associar um vínculo estatutário a um celetista.

Das sete enfermeiras com renda mensal entre $\mathrm{R} \$ 3.501,00$ e $\mathrm{R} \$ 6.000,00$, cinco possuem apenas um vínculo, sendo quatro contratadas por meio da CLT e uma estatutária. As outras duas participantes, que também se encontram nessa faixa salarial, referiram manter dois vínculos, uma acumulando dois vínculos estatutários e a outra acumulando um vínculo estatutário e um contrato CLT.

Quanto às jornadas de trabalho, a maioria das participantes desenvolve suas atividades profissionais no centro obstétrico. Entretanto, em função do acúmulo de vínculos, à essas atividades somam-se a atuação no setor de acolhimento e classificação de risco (citado por 6 enfermeiras obstétricas) e/ou no pré-natal (pontuado por 2 enfermeiras obstétricas). Desse modo, ao atuarem em diferentes espaços ocupacionais, nove $(60,00 \%)$ participantes afirmaram trabalhar por 60 horas semanais, três $(20,00 \%)$ por 30 horas, duas $(13,33 \%)$ por 40 horas e uma $(6,66 \%)$ por 50 horas.

Como um dos efeitos do capitalismo sobre o processo de trabalho, tem-se a separação entre o homem e os meios de produção, com a consequente alienação do trabalhador acerca das condições objetivas de seu trabalho, pois o modelo produtivista o coloca numa posição social de subalternidade ao capital, incorrendo na perda do controle sobre sua vida material ${ }^{10}$. Essas condições se expressam na divisão do trabalho, na posse dos meios de produção, na conjuntura, nos objetos e campos de intervenção, nos espaços ocupacionais, nas relações laborais, nos recursos utilizados pelos trabalhadores, na desregulamentação dos vínculos, nos baixos salários, na rotatividade e fragmentação do trabalho ${ }^{9}$.

Em relação à natureza das relações laborais estabelecidas entre as participantes e a esfera pública, verificou-se a prevalência de vínculos regidos pela CLT em detrimento ao regime estatutário. Tal constatação decorre da reestruturação produtiva em curso nos serviços de saúde públicos brasileiros, os quais vêm adotando novos formatos para a gestão dos serviços e dos recursos humanos, principalmente por meio de OS, com a justificativa de melhorar a qualidade e eficiência do SUS ${ }^{3}$.

Entretanto, esse discurso de inovação gerencial emergiu num panorama adverso de limitações nos investimentos para o SUS que, somado à complexidade de sua estrutura burocrática e às restrições impostas sobre o regime estatutário, reforçaram a representação de incapa- cidade administrativa da máquina pública e a necessidade de participação da iniciativa privada, com a consequente introdução da lógica mercadológica do capital nos serviços públicos ${ }^{11}$. Para tanto, foram criados dispositivos legais que possibilitaram mudanças na forma de contratação e estruturação da força de trabalho, com destaque para a Emenda Constitucional no 19/1998, que reconfigurou o campo laboral do SUS a partir de novas modalidades de vinculação para os profissionais, com a coexistência de trabalhadores da saúde estatutários, celetistas, temporários e terceirizados ${ }^{7,12}$.

Ressalta-se que a adoção de práticas flexíveis de contratação no campo da saúde brasileira teve início em meio aos processos de descentralização e municipalização, ganhando força com novas políticas e programas de execução local, como: o Programa Saúde da Família, o Programa dos Agentes Comunitários de Saúde, o Serviço de Atendimento Móvel de Urgência e, mais recentemente, a Rede Cegonha e o Programa Cegonha Carioca 5 .

Sob a égide da flexibilização, proliferaram vínculos de trabalho precário no SUS, definido como aquele que é exercido em condições nas quais o trabalhador se encontra em situação de risco, fragilidade e vulnerabilidade ${ }^{13}$. Nesse sentido, as atividades no setor informal, os empregos terceirizados e temporários no setor formal são exemplos clássicos de trabalho precário por conformarem vínculos frágeis que não asseguram os devidos direitos trabalhistas e previdenciários. A esses, acrescentam-se as formas de ingresso na administração pública que não sejam por meio de concurso, as quais constituem irregularidades pela desobediência às normas vigentes do direito administrativo e do trabalho ${ }^{14}$.

Com base nessas considerações, constatou-se que as treze enfermeiras obstétricas que possuem, pelo menos, um vínculo regido pela CLT, ainda que gozem de direitos laborais, encontram-se na condição de trabalho precário por não atenderem às regras de investidura no serviço público, uma vez que foram admitidas através de um processo seletivo envolvendo apenas avaliação de títulos ${ }^{15}$.

Por outro lado, no caso das cinco enfermeiras obstétricas que estão sob o regime estatutário, apesar da estabilidade desse tipo de vínculo, a precariedade reside nas condições de trabalho. Essas condições indicativas de precariedade podem ser decorrentes da ausência de reajustes salariais, da inexistência de um plano de carreira, do crescimento de formas variáveis de remuneração entre estatutários e, principalmente, da relação com outros trabalhadores da mesma categoria ${ }^{11}$. Nesse panorama, com a incorporação da lógica do capital na gestão do SUS, os sentidos atribuídos ao trabalho no setor público se aproximam daquelas típicas do setor privado ${ }^{2,7}$.

Como efeito, evidencia-se a precarização do trabalho no SUS, fruto da multiplicidade de realidades laborativas e da dificuldade de regulação das mesmas. 0 enfrentamento dessa problemática vem sendo feito com programas e ações estratégicas, destacando-se a criação do Departamento de Gestão e da Regulação do Trabalho 
em Saúde, do Programa Nacional de Desprecarização do Trabalho no SUS e do Programa de Qualificação e Estruturação da Gestão do Trabalho e da Educação no SUS ${ }^{14}$.

Apesar desses esforços, algumas questões permanecem longe da discussão, como as diferenças salariais existentes entre trabalhadores estatutários e celetistas $^{12}$. No caso das participantes desse estudo, à essas desigualdades delineadas pela natureza da relação de trabalho, soma-se a remuneração diferenciada entre profissionais que exercem a mesma atividade (o cuidado ao parto normal), circunscrita entre enfermeiras obstétricas e médicos obstetras.

Comparando-se o salário base oferecido no último concurso público para o provimento de enfermeiras em cargo efetivo na Secretaria Municipal de Saúde do Rio de Janeiro, publicado em 2013, com o disposto no edital de um processo seletivo para a contratação de enfermeiras obstétricas, realizado em 2014 por uma OS, constata-se que, mesmo com os reajustes anuais, a OS oferece um salário 108,14\% maior do que está estabelecido para os profissionais sob o regime estatutário. Essa discrepância é ainda maior quando confrontada com o salário dos médicos obstetras contratados pela OS, alcançando um valor $257,88 \%$ superior ao recebido pelas enfermeiras obstétricas estatutárias ${ }^{15-17}$.

Frente à essas distinções, nota-se que os profissionais de saúde são melhores remunerados quando contratados por meio das OS. Tal fato corrobora para a disseminação de representações negativas acerca do trabalho no serviço público que, ao permitir condições diferenciadas de remuneração entre profissionais que exercem a mesma atividade, desagrega o ideário coletivo de luta entre os trabalhadores, criando mais obstáculos para a consolidação do SUS ${ }^{7,10}$.

Ainda, ao praticar salários tão desiguais entre profissionais da mesma categoria e especialidade, emergem competições internas entre as enfermeiras obstétricas que contribuem para a degradação da ambiência no serviço. Assim, aquelas que recebem salários maiores, adentram no modo de produção capitalista do setor privado, buscando a produtividade através de práticas, muitas vezes, repetitivas, com foco em aspectos técnicos e na otimização do tempo de produção ${ }^{18}$. Enquanto isso, as que se encontram em defasagem salarial percebem a desvalorização de seu processo de trabalho e sentem-se desmotivadas.

Essa conformação entre as enfermeiras obstétricas que atuam no setor público, com diferenças salariais exacerbadas e relações laborais particularizadas, resulta na fragmentação da força de trabalho na enfermagem ${ }^{12}$, enfraquecendo o poder de mobilização dessas trabalhadoras para lutar pelo reconhecimento e valorização do trabalho na especialidade, o qual encontra-se precarizado em comparação aos salários oferecidos aos médicos obstetras.

Diante disso, é possível afirmar que as estatutárias estão submersas num processo de trabalho precarizado visto que, na relação com enfermeiras obstétricas e médicos dotados de vínculo celetista com a OS, recebem salários menores e, por isso, podem se perceber exploradas e desvalorizadas no campo obstétrico. Nessa vertente, evidencia-se uma das faces da precarização do trabalho no SUS que atinge, inclusive, os servidores com vínculos estáveis e alta escolaridade ${ }^{18}$.

Ademais, ao oferecer salários superiores aos praticados no regime estatutário, a OS induz os profissionais celetistas à trabalharem mais intensamente para atingir metas de produção e justificar os salários recebidos. Além disso, cabe ressaltar o fato das enfermeiras estatutárias receberem a mesma remuneração independente do setor de atuação e da natureza das atividades desenvolvidas, assim como não há diferenças salariais entre as celetistas que atuam no centro obstétrico e as lotadas no setor de acolhimento. Essa realidade mostra a desvalorização do capital científico das enfermeiras obstétricas, pelo não reconhecimento do título de especialista, e das especificidades de seu processo de trabalho nas salas de parto.

Com isso, identifica-se a polivalência laboral, definida como a multiplicação das habilidades intelectuais e das capacidades do trabalhador em realizar tarefas diversificadas, desempenhar e ocupar diferentes funções e postos de trabalho ${ }^{19}$. Essa exigência pela multifuncionalidade das enfermeiras obstétricas no processo produtivo das salas de parto, revela a flexibilização dessas trabalhadoras, um instrumento necessário à reestruturação produtiva em curso no setor público.

Nota-se também uma contradição entre o discurso programático do SUS e sua operacionalização nos serviços de saúde à medida que investir na inserção de enfermeiras obstétricas nas salas de parto das maternidades é uma recomendação das políticas públicas de saúde da mulher para humanizar e qualificar a assistência obstétrica ${ }^{4,5}$. Entretanto, ao passo em que se reconhece o papel ativo dessas especialistas para o alcance de tais objetivos, não há valorização concreta das mesmas, pois o vínculo de trabalho estabelecido desconsidera o volume de capital científico necessário para o exercício profissional nas salas de parto, ou seja, o conjunto de saberes, habilidades, competências e atitudes próprias da especialidade.

Apesar da valorização das enfermeiras obstétricas nas políticas, a absorção dessas especialistas no mercado laboral do SUS sem a devida remuneração por sua qualificação e especialização revela outra vertente da precarização, expressa pela desvalorização social do trabalho que se materializa na discrepância salarial encontrada entre médicos obstetras e as participantes desse estudo.

Tal desvalorização resulta da divisão sexual do trabalho, enquanto uma forma de divisão social do trabalho, modulada histórica e socialmente, a partir da concepção de trabalho masculino sendo destinado à esfera produtiva e o trabalho feminino à esfera reprodutiva doméstica. Nessa perspectiva, conformam-se desigualdades de gênero, com homens desempenhando trabalhos de maior visibilidade e hierarquicamente superiores, enquanto as mulheres, quando adentram 
no espaço público produtivo, recebem remunerações inferiores e sofrem com a desqualificação de seu trabaIho, independente do grau de escolaridade ${ }^{20,21}$.

Assim, as enfermeiras obstétricas, mulheres de uma profissão feminina associada ao cuidado humano, inseridas numa especialidade que requer habilidades relacionais ligadas à natureza e ao feminino, têm seu processo de trabalho desqualificado frente ao status social que a profissão médica incorpora numa sociedade marcada pelo princípio androcêntrico e pela dominação masculina ${ }^{21-23}$.

Como efeito dessas desigualdades de gênero decorrentes da divisão sexual do trabalho em saúde, é comum as enfermeiras possuírem mais de um emprego, assumindo longas jornadas de trabalho no mundo produtivo, além das atividades não remuneradas desenvolvidas na esfera privada ${ }^{5,18}$. Nesse sentido, a enfermagem é reconhecida como a categoria mais propensa ao adoecimento em função de suas intensas jornadas de trabalho, principalmente, quando atuam em unidades de internação ${ }^{18,19}$.

Essa também é a realidade das condições de trabaIho das participantes desse estudo, pois a maioria refere ter renda mensal superior à $\mathrm{R} \$ 6.000,00$ por acumular dois vínculos empregatícios, trabalhando em jornada semanal de 60 horas, grande parte dela desenvolvida no setor do centro obstétrico. Tal situação aponta para a intensificação laboral, definida pelo aumento do grau de intensidade do trabalho que se expressa no prolongamento das jornadas, no aumento do ritmo e da velocidade das atividades, no acúmulo de funções, na exigência pela polivalência e flexibilidade, na busca pela produtividade e na remuneração variável ${ }^{18,19,23}$.

Em curso nas últimas décadas, esse processo vem afetando várias categorias profissionais dos setores públicos e privados, sendo comum entre os trabalhadores da saúde, sobretudo as enfermeiras por estarem mais envolvidas no cuidado direto à clientela e por ser frequente o acúmulo de empregos em função dos baixos salários. Nesse grupo, a intensificação também resulta do desgaste psíquico, da complexidade e heterogeneidade das atividades desenvolvidas no ambiente hospitalar, as quais se configuram como sobrecarga por agregar um volume maior de trabalho material e imaterial ${ }^{19,24}$.

A princípio, o trabalho deveria ser fonte de satisfação e realização profissional, entretanto, em condições de intensificação laboral, pode ser um fator gerador de estresse, insatisfação e frustração, que compromete a capacidade funcional e moral dos trabalhadores, com impactos importante sobre a qualidade dos serviços ${ }^{12,19,24}$.

Nesse sentido, nota-se que as enfermeiras obstétricas que atuam no SUS se encontram mais suscetíveis aos efeitos da intensificação visto que muitas condições objetivas de seu processo de trabalho apontam para a precarização, conforme apresentado na Figura 1:

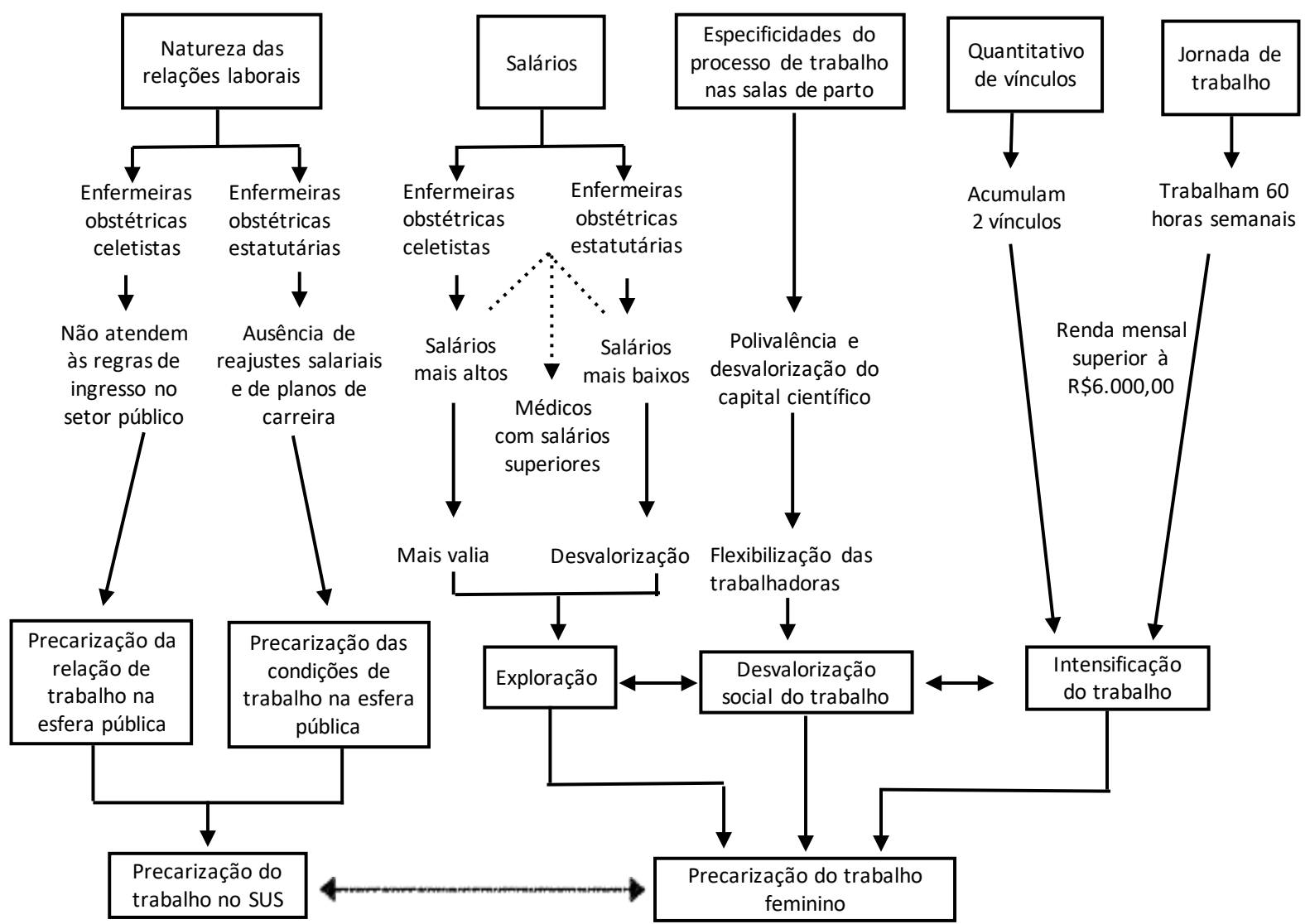

FIGURA 1: As dimensões da precarização do trabalho das enfermeiras obstétricas a partir das condições objetivas de seu processo de trabalho no SUS. Rio de Janeiro, Brasil, 2016. 


\section{CONCLUSÃO}

Como efeito da reestruturação produtiva implementada no SUS, as enfermeiras obstétricas mantém relações laborais com a administração pública através do regime estatutário e, principalmente, do celetista intermediado por OS. Apesar da formalidade dessas vinculações, elas se encontram num trabalho precário, pois as celetistas não obedecem às regras de ingresso no serviço público e as estatutárias são diretamente afetadas pelas restrições orçamentárias do SUS.

As exacerbadas diferenças salariais constatadas entre trabalhadores que desenvolvem a mesma atividade revelaram a divisão sexual do trabalho, pois as enfermeiras estatutárias possuem salários mais baixos em relação às celetistas e os médicos obstetras recebem salários muito superiores. Além disso, não há o reconhecimento do capital científico das enfermeiras obstétricas visto que não são remuneradas pelo exercício na especialidade, trazendo a noção de flexibilização que remete à desvalorização social de seu processo de trabalho.

Assim, a maioria das participantes possui longas jornadas de trabalho e acumulam dois vínculos laborais para alcançar uma renda mensal mais próxima de suas demandas. Nesse panorama, exploração, desvalorização e intensificação são características incorporadas ao processo de trabalho das enfermeiras obstétricas, as quais evidenciam a precarização do trabalho feminino no setor público.

Para além dos prováveis efeitos deletérios dessa configuração sobre a vida das enfermeiras obstétricas, há de se considerar os impactos negativos da fragmentação dessa força de trabalho sobre a luta coletiva da especialidade pela valorização e reconhecimento social. Ainda, à longo prazo, a precarização pode desencadear a saída dessas especialistas das salas de parto, comprometendo a efetivação das políticas públicas da saúde da mulher que reforçam a essencialidade das enfermeiras obstétricas.

Assim, é fundamental que essas especialistas fortaleçam sua unidade de classe a fim de elaborar estratégias para o enfrentamento das condições objetivas que vem deteriorando seu processo de trabalho, com potencial para comprometer sua saúde e o cuidado à mulher.

Não obstante, atentamos para refletir sobre as repercussões do avanço da lógica capitalista no serviço público que, ao produzir representações depreciativas acerca do trabalho no SUS, cria mais obstáculos para sua consolidação.

O estudo teve como limitaçao o reduzido número de partricipantes, devido à redução de enfermeiras obstétricas atuantes nas maternidades, causa e consequência da precarização do trabalho dessas enfermeiras.

\section{REFERÊNCIAS}

1. Massimo L. Como se explica o neoliberalismo no Brasil? Uma análise crítica dos artigos publicados na Revista Dados. Rev. Sociol. Polít. [periódico da internet]. 2013 [citado em 2017 ago 23]; 21(47):133-
87. Disponível em: http://www.scielo.br/scielo.php?pid=S0104$-44782013000300010 \&$ script=sci_abstract \&tIng=pt

2. Marques APP. Reestruturação produtiva e recomposições do trabalho e emprego. Um périplo pelas "novas" formas de desigualdade social. Ciênc saúde coletiva. (Online). 2013 [citado em 23 ago 2017]; 18(6):1545-54. Disponível em: http://www.scielo.br/scielo. php?script=sci_abstract\&pid=S1413-81232013000600007\&lng=es \&nrm=iso\&tlng=pt

3. Prata JA, Progianti JM, David HSL. A reestruturação produtiva na área da saúde e da enfermagem obstétrica. Texto \& contexto enferm. (Online). 2014 [citado em 23 ago 2017]; 4(23):1123-9. Disponível em: http://www.scielo.br/pdf/tce/v23n4/pt_01040707-tce-23-04-01123.pdf

4. Progianti JM, Prata JA, Barbosa PM. A reestruturação produtiva na saúde: os efeitos da flexibilização nas maternidades do Programa Cegonha Carioca. Rev. enferm. UERJ. (Online). 2015 [citado em 23 ago 2017]; 23(2):164-71. Disponível em: http://www.facenf.uerj. br/v23n2/v23n2a04.pdf

5. Pereira ALF, Nicácio MC. Formação e inserção profissional das egressas do curso de residência em enfermagem obstétrica. Rev. enferm. UERJ. (Online). 2014 [citado em 23 ago 2017]; 22(1):50-6. Disponível em: http://www.e-publicacoes.uerj.br/index.php/enfermagemuerj/article/view/11418/8977

6. Leal MC, Pereira APE, Madeira MRS, Theme Filha MM, Dias MAB, Pereira $M N$ et al. Intervenções obstétricas durante o trabalho de parto e parto em mulheres brasileiras de risco habitual. Cad. Saúde Pública. (Online). 2014 [citado em 23 ago 2017]; 30(suppl. 1):17-47. Disponível em: :http://dx.doi.org/10.1590/0102-311X00151513

7. Martins MIC, Molinaro A. Reestruturação produtiva e seu impacto nas relações de trabalho nos serviços públicos de saúde no Brasil. Ciênc saúde coletiva. (Online). 2013 [citado em 23 ago 2017]; 18(6):1667-76. Disponível em: http://www.scielo.br/scielo. php?script=sci_abstract\&pid=S1413-81232013000600018\&lng=pt \&nrm=iso\&tlng=pt

8. Moreira NJMP. Precarização do trabalho no campo obstétrico: percepções de enfermeiras [dissertação]. Rio de Janeiro: Universidade do Estado do Rio de Janeiro; 2017.

9. Santos MT, Manfroi VM. Condições de trabalho das/os assistentes sociais: precarização ética e técnica do exercício profissional. Em Pauta. [periódico da internet]. 2015 [citado em 23 ago 2017]; 13(36):178-96. Disponível em: http://www.e-publicacoes.uerj.br/ index.php/revistaempauta/article/view/21057/15716

10. Duck G. A terceirização na saúde pública:formas diversas de precarização do trabalho. Trab. Educ. Saúde. [periódico da internet] 2016 [citado em 23 ago 2017];14 (suppl. 1):15-43. Disponível em: https://dx.doi.org/10.1590/1981-7746-sol00023

11. Ribeiro CVS, Mancebo DO. O servidor público no mundo do trabalho do século XXI. Psicol. Ciênc. Prof. [periódico da internet]. 2013 [citado em 23 ago 2017]; 33(1):192-207. Disponível em: http://www.scielo.br/scielo.phpscript=sci_arttext\&pid =S1414-98932013000100015

12. Ribeiro AC, Souza JF, Silva JL. A precarização do trabalho no SUS na perspectiva da enfermagem hospitalar. Cogitare enferm. Rev. (Online). 2014 [citado em 23 ago 2017]; 19(3):569-75. Disponível em: http://revistas.ufpr.br/cogitare/article/view/33034/23247

13. Dedecca CS, Trovão CJBM. A força de trabalho no complexo da saúde: vantagens e desafios. Ciênc. saúde coletiva. (Online). 2013 [citado em 23 ago 2017];18(6):1555-67. Disponível em: http://www. scielo.br/scielo.php?pid=S1413-81232013000600008\&script=sci abstract\&tlng=es

14. Ministério da Saúde (Br). Gestão do trabalho e da regulação profissional em saúde: agenda positiva do Departamento de Gestão e da Regulação do Trabalho em Saúde. 3a ed. Brasília (DF): Ministério da Saúde; 2009.

15. Centro de estudos e pesquisa 28. Organização Social em Saúde Edital no 16 de 30 de dezembro de 2014. Dispõe sobre o Processo Seletivo de vagas e formação de cadastro reserva para Enfermeiros Obstetras HMMR - Cegonha Carioca. [Internet]. [citado em 23 ago 
2017]. Disponível em: http://www.cep28.org.br/transparencia/ processos-seletivos-2014/.

16. Rio de Janeiro. Secretaria Municipal de Saúde. Edital no 144 de 3 de junho de 2013. Regulamenta o concurso público para provimento de cargos de nível superior, médio e fundamental completos, prioritariamente, no âmbito da secretaria municipal de saúde do município do Rio de Janeiro. [Internet]. [citado em 23 ago 2017] Disponível em: http://doweb.rio.rj.gov.br/visualizar_pdf.php?edi_id=2086\&page=1 17. Centro de estudos e pesquisa 28. Organização Social em Saúde. Edital no 01 de 05 de janeiro de 2016. Dispõe sobre o processo seletivo de vagas para médicos obstetras. [Internet]. [citado em 23 ago 2017] Disponível em: https://www.cep28.org.br/transparencia/ edital-processo-seletivo-medico-obstetra/

18. Melo CMM, Carvalho CA, Silva LA, Leal JAL, Santos TA, Santos HS. Força de trabalho da enfermeira em serviços estaduais com gestão direta: Revelando a precarização. Esc. Anna Nery Rev. Enferm. (Online). 2016 [citado em 23 ago 2017]; 20(3):e20160067. Disponível em: http://www.scielo.br/scielo.php?pid=S1414$-81452016000300211 \&$ script=sci_abstract\&tlng $=p t$

19. Gonçalves FGA, Souza NVDO, Pires AS, Santos DM, D`Oliveira CAFB, Ribeiro LV. Modelo neoliberal e suas implicações para a saúde do trabalhador de Enfermagem. Rev. enferm. UERJ. (Online). 2014 [citado em 23 ago 2017]; 4(22):519-25. Disponível em: http://www. facenf.uerj.br/v22n4/v22n4a14.pdf

20. Pereira AV. O cotidiano de enfermeiras e enfermeiros: relações de gênero, a partir do tempo no hospital. Rev. latinoam. enferm. (Online). 2015 [citado em 23 ago 2017]; 23(5):945-53. Disponível em: http:// www.scielo.br/pdf/rlae/v23n5/pt_0104-1169-rlae-23-05-00945.pdf 21. Mies M. Origens sociais da divisão sexual do trabalho. A busca pelas origens sob uma perspectiva feminista. Rev. Direito e Práx. [periódico da internet]. 2016 [citado em 23 ago 2017]; 7(15):838-73. Disponivel em: http://www.redalyc.org/articulo.oa?id=350947688027 22. Bourdieu P. A dominação masculina. Tradução de Maria Helena Kuhner. $2^{a}$ ed. Rio de Janeiro: Bertrand Brasil; 2002.

23. Souza MMT, Passos JP, Tavares CMM. Sofrimento e precarização do trabalho em enfermagem. Rev. pesqui. cuid. fundam. (Online). 2015 [citado em 23 ago 2017]; 7(1):2072-82. Disponível em: http://www.seer.unirio.br/index.php/cuidadofundamental/article/ view/1515/pdf_1456

24. Dodou HD, Sousa AAS, Barbosa EMG, Rodrigues DP. Sala de parto: condições de trabalho e humanização da assistência. Cad. Saúde Colet. (Online). 2017 [citado em 23 ago 2017]; 25(3):3328. Disponível em: http://www.scielo.br/scielo.php?pid=S1414$-462 X 2017000300332 \&$ script=sci_abstract\&tlng=pt 